\title{
Effect of Two-Dimensional Profile Optimization on Vertical Axis Wind Turbine Power Performance
}

\author{
Cemil YiĞiT*, Erdem AKMAN
}

\begin{abstract}
In this study, performance of the blade profiles which was developed numerically and parametrically was examined experimentally for vertical axis wind turbine. In the parametric optimization study, angle of attack, mean (camber) line and thickness were taken as parameter, and the profile was optimized by using Ansys/Response Surface Optimization tool. After that, in the numerical optimization study, the lift and drag coefficients were taken as parameters and the profile was optimized and the blade profiles of NACA0012- $\alpha$ and NACA0012- $\beta$, which would make the lift-to-drag ratio maximum, were obtained. The developed profiles were produced by 3D printer and the power data was measured experimentally for 3,4 and 5 bladed turbines. The highest power was obtained in the 4 -bladed turbine for all profiles. The power coefficient of 0.19 was obtained from a reference profile, while power coefficient of 0.24 was obtained from NACA0012- $\alpha$ profile and 0.30 from NACA0012- $\beta$ profile. The blade profile derived by numerical optimization reached $25 \%$ higher power coefficient than the blade profile derived by parametric optimization. It is found that lift coefficient on the power coefficient of the vertical axis wind turbine is more dominant than the drag coefficient.
\end{abstract}

Keywords: adjoint solver; blade profile; computational fluid dynamics; optimization; vertical-axis wind turbine

\section{INTRODUCTION}

The need for energy has been increasing with the increasing population and advanced technologies. Most of the energy requirements in the world are derived from fossil fuel sources such as petroleum, natural gas and coal. The damage to the environment caused by harmful substances due to the use of fossil fuels has been increasing and it is believed that it would be inevitable to see the natural balance at a phase in the future which will no longer be irreversible. On the other hand, they include both political and economic constraints since fossil resources in certain regions and reserves are limited. It is highly possible that alternative sources and methods will replace the fossil fuel-based power generation methods in the world in the near future due to increasing demand and limited resources.

Developed countries prepare projects to meet their energy needs from renewable energy sources and they derive a large part of their energy needs gradually from processes using clean and renewable energy sources. As a government policy in developing countries incentives are given and opportunities are provided for various investments in order to increase the interest in renewable energy resources and reduce dependence on foreign countries.

One of the clean and renewable energy sources, wind energy comes into prominence because of the decrease in investment costs of wind turbines and unit energy cost. Although three bladed and horizontal axis wind turbines taking the wind from the front are commercialized today, the use of vertical axis wind turbines (VAWT) has become widespread in recent years because of low cut-in speed, aesthetic structures, and noise. In addition, studies on improving the performance of VAWTs have had a positive effect on the increase of the usage of turbines.

Some researchers [1-4] focused on shape optimization of the blade to improve the turbine performance, while others took parameters such as number and angle of blades as well as geometry. Erisen \& Bakirci [5] created three new geometries over standard blade geometries of NACA0012 and NACA4412 by taking upper and lower surface as parameters, obtained the lift coefficient (CL) values at 4, 8 and 12 attack angles by using the k-epsilon turbulence model and determined that the derived blade profiles give better results than the referenced blade profiles. In their study on H-rotor VAWT, Li et al. [6] reported that the optimized blade pitches can increase the power coefficient. Karimian \& Abdolahifar [7] proposed a new configuration, which they called the three-part-blade wind turbine, in their studies where they examined the aerodynamic performance of the Darrieus type vertical axis wind turbine. They reported that this new turbine operated with high output torque without too much torque fluctuation.

Many researchers [8-10] carried out numerical optimization of the blade profile by using Computational Fluid Dynamics (CFD) method in their studies. Gomec [11] performed time-dependent two-dimensional numerical analysis for NACA0021 blade profile at constant wind speed using CFD software for Darrieus type turbines with 2 and 3 blades and he found that 2-bladed turbines achieved optimum operating conditions at relatively low tip-speed ratio (TSR), while 3-bladed turbines cut-in speed was lower and it ran more stable. In their study, Castelli et al. [12] investigated the effect of the number of blades used in the turbine on the rotor performance of the flat-blade Darrieus type wind turbine with two-dimensional CFD analysis. They studied the torque and the power coefficients for different TSR for 3 , 4 and 5 blades using the NACA 0025 blade profile and they found that high power can be obtained at low angular velocities due to the increase in the number of blades. In the studies where they examined aerodynamic behaviour on the blade by taking into account the interactions on parameter values affecting performance such as rotor diameter, angle of attack, helical angle of blade and chord length in Darrieus type wind turbines; Lee \& Hee [13] have noted that the power coefficient increases at low TSR as the solidity increases, but it decreases at high TSR by being affected by increasing drag forces. In the study where they analyzed NACA0012 blade profile experimentally and numerically at low attack angles and determined which turbulence model was more compatible with experimental results, Bekka et al. [14] used Spalt-Allmaras, Baldwin- 
Lomax, $k-\omega, k-\omega$ SST turbulence models and found that models other than $k-\omega$ have close results with experimental data. Sabaeifard et al. [15] performed CFD analysis using $\mathrm{k}-\varepsilon$ turbulence model for different blade numbers, profile types and turbine solidity rates and for the H-Type Darrieus wind turbine with a design suitable for urban areas and they found that 3-bladed turbine had better performance compared with other turbines.

Some studies have also focused on reducing the cut-in speed of the turbine. In their experimental studies carried out on 3 different blade profiles commonly used in literature, Yilmaz et al. [16] studied the aerodynamic performance of profiles at 6,7 and $8 \mathrm{~m} / \mathrm{s}$ speeds and at $-4^{\circ}$ to $26^{\circ}$ attack angles. The results show that the lift-to-drag $(\mathrm{CL} / \mathrm{CD})$ ratio on the NACA63-415 blade profile at $4^{\circ}$ to $12^{\circ}$ attack angles was approximately 2 times higher than the other profiles. Yao et al. [17], for NACA0018 profile; Sahin \& Acir [18] for NACA0015 profile examined lift and drag (CD) coefficients numerically and experimentally in low Reynolds numbers and different attack angles, and they found that the Spalart-Allmaras turbulence model gave closer results to the experimental data.

In the optimization stage of this study, based on the NACA0012 profile which is commonly used in the literature, new profiles were developed with parametric and numerical optimization methods. Optimized profiles were used on the vertical axis H-Type Darrieus wind turbine and turbine performance was analyzed by taking the number of blades as parameters. In the scope of the parametric study, angle of attack, the mean line and thickness of the blade profile were systematically changed between maximum and minimum value to obtain an orthogonal test matrix, and then the parameter levels were determined which obtained maximum lift-to-drag ratio using respond surface optimization (RSO) method. Then, numerical optimization studies were performed using Ansys/Fluent Adjoint Solver software. The profiles obtained were produced by the additive manufacturing method and power data was experimentally obtained from the VAWT. In the present study, power performance characteristics of the VAWT were investigated, and then two dimensionally optimized profiles under static conditions were also examined on the results of experimental study under dynamic conditions. Thus, the validity of the optimization study which was carried out under static condition, unlike in the reviewed literature, was examined under dynamic conditions.

\section{NUMERICAL STUDY}

A two-dimensional computational area was set using ANSYS/Design Modeler module and simulations were carried out by using ANSYS/Fluent module in order to perform numerical studies. The implicit Navier-Stoke algorithm was performed as solver method in the study. Realizable $k$ - $\omega$ turbulence model was used for modelling the turbulence of the air flow. The continuity and momentum equations were solved. "Coupled" scheme was used as the pressure velocity coupling. At the initial stages of the analysis, a first order-upwind scheme was used for discretizing the convective terms, for enhancing convergence. However, the final results were obtained by using a second-order upwind scheme for improved accuracy.
Since VAWT operated at low free stream velocity in experimental and numerical studies, the air was considered incompressible. The continuity equation for incompressible flow and momentum equation in conservative form were given for all coordinate systems in Eq. (1) and (2), respectively.

$$
\begin{aligned}
& \frac{\partial \rho}{\partial t}+\vec{\nabla}(\rho \vec{V})=0 \\
& -\vec{\nabla} P+\rho \vec{g}+\mu \nabla^{2} \vec{V}=\frac{\partial}{\partial t}(\rho \vec{V})+\vec{\nabla} \cdot(\rho \vec{V} \vec{V})
\end{aligned}
$$

For the selected turbulence model, the equations expressed by turbulence kinetic energy $(k)$ and turbulence dissipation rate $(\varepsilon)$ are given in Eq. (3) and (5), respectively. Moreover, the constant coefficients of the equation are defined as $C_{1}=1.44, C_{2}=1.92, \sigma_{k}=1.0, \sigma_{s}=$ 1.2 and $C_{\mu}=0.09$ [19].

$$
\begin{aligned}
& \frac{\partial}{\partial t}(\rho k)+\frac{\partial}{\partial x_{i}}\left(\rho k u_{i}\right)=\frac{\partial}{\partial x_{j}}\left[\left(\mu+\frac{\mu_{t}}{\sigma_{k}}\right) \frac{\partial k}{\partial x_{j}}\right]+\zeta_{1} \\
& \zeta_{1}=G_{k}-\rho \varepsilon \\
& \frac{\partial}{\partial t}(\rho \varepsilon)+\frac{\partial}{\partial x_{i}}\left(\rho \varepsilon u_{i}\right)=\frac{\partial}{\partial x_{j}}\left[\left(\mu+\frac{\mu_{t}}{\sigma_{\varepsilon}}\right) \frac{\partial \varepsilon}{\partial x_{j}}\right]+\zeta_{2} \\
& \zeta_{2}=C_{1} \frac{\varepsilon}{k} G_{k}-C_{2} \rho \frac{\varepsilon^{2}}{k}
\end{aligned}
$$

In these equations, $G_{k}$ shows the generation of turbulence kinetic energy owing to the mean velocity gradients. $\sigma_{k}$ and $\sigma_{\varepsilon}$ in the equation show the turbulent Prandtl number for $k$ and $\varepsilon$, respectively. Turbulent viscosity $\left(\mu_{t}\right)$ is calculated as a function of $k$ and $\varepsilon$ and can be calculated by the following relation:

$\mu_{t}=\rho C_{\mu} \frac{k^{2}}{\varepsilon}$

Within the scope of CFD analysis, blade profile and surrounding calculation area were prepared in twodimensions. The model was kept sufficiently wide to ensure that the blade profile was not affected by the boundary conditions of the calculation zone.

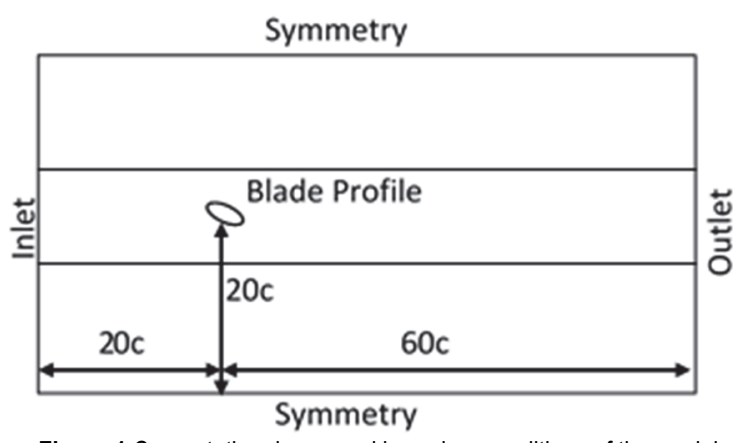

Figure 1 Computational area and boundary conditions of the model 
The boundary conditions of the calculation area were defined as in Fig. 1. Boundary conditions were assigned to the inlet section of the calculation area as "Inlet", for outlet section as "pressure outlet", for top and the bottom section as "symmetry" and for profile boundary as "wall".

The grid structure of mesh containing triangular elements was preferred for CFD analysis. The quality of the mesh is extremely important for the accuracy of the results. Therefore, relatively smaller mesh elements were used on the surface using a weight function. On the other hand, the boundary layer was defined on the surface to better capture the surface interaction with the flow. Moreover, special attention was given to keep the maximum skewness $(<0.98 ; 0.83-0.95)$ and orthogonal quality $(>0.10 ; 0.12-0.50)$ values of the mesh elements within acceptable limits in the literature. The grid structure of the two-dimensional computational field is shown in Figs. $2 \mathrm{a}$ and $2 \mathrm{~b}$, respectively, as wide angle and close angle. The turbulence model for $y^{+}$values between 1 and 5 on the profile surface provides wall shear stresses compatible with experimental data [20]. Although the model does not reach $y^{+}$value of around 1 , it remains below 5. Reducing $y^{+}$to 1 for the prepared model brings a serious processor and RAM load to the analysis.

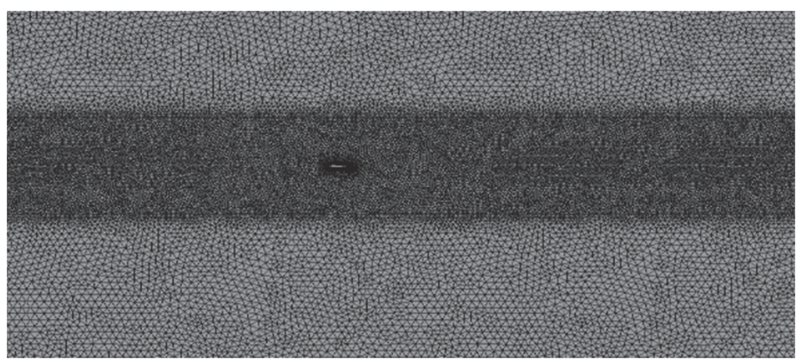

(a)

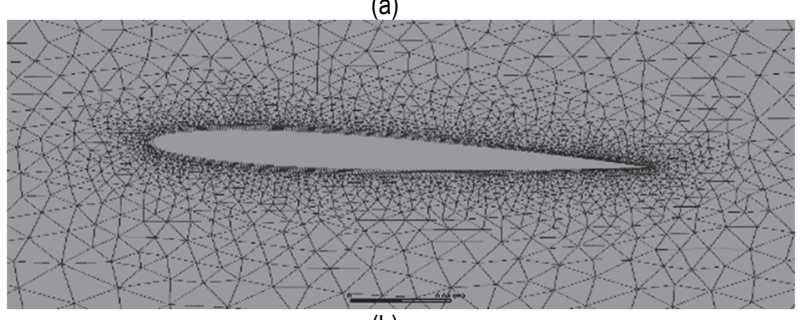

(b)

Figure 2 Grid structure of the computational domain

Within the scope of the independent study of CFD analysis from the mesh, grid structures with a different number of elements were analyzed. The lift-to-drag ratio values were obtained for mesh with a number of elements from $100 k$ to $500 k$. Increasing the number of elements in the mesh after about $300 k$ elements has a very small $(<$ 0.001 ) impact on the result. Therefore, the mesh with $300 k$ element number was used in CFD analyzes.

\subsection{Parametric Optimization}

In the parametric study, angle of attack, mean line and thickness of the blade profile were taken as parameters and the optimized blade profile which has maximum lift-todrag ratio using RSO method was determined. These parameters were systematically changed between maximum and minimum value to obtain an orthogonal test matrix including 3 parameters and 8 degrees of freedom. The angle of attack was changed $\pm 10^{\circ}$, while the profile thickness and the position of the mean line on the $y$-axis were changed by a maximum of $\pm 40 \%$. Lift-to-drag ratio values for each profile geometry were generated using twodimensional CFD analyses. Parameter levels giving the highest lift-to-drag ratio were determined. ANSYS software produced 22 variations in the specified optimization parameters and range of values. Optimization work was performed with the RSO method for maximizing lift-to-drag ratio of the profile.

Blade profile was created by using RSO method in order to examine the effect of shape parameters such as angle of attack, mean line and thickness on lift-to-drag ratio of the profile, increase the VAWT's power output. The RSO method is a targeted and multi-objective optimization method that provides the best possible design in accordance with the constraints and objectives set for the optimization parameters.

For the blade profile with a chord length of $0.08 \mathrm{~m}$, the maximum lift-to-drag ratio was obtained at an approximately attack angle of $5^{\circ}$ in two-dimensional CFD analyses performed in the range of Reynold numbers between 16000 and 32000 . Mean line which is positioned between upper and lower surface of the blade profile in Cartesian coordinate system and thickness of the blade profiles are shown in Fig. 3.

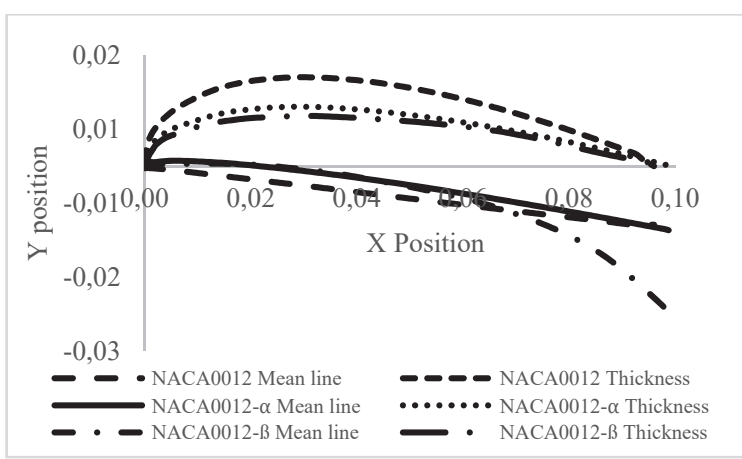

Figure 3 Mean line and thickness of the NACA0012, NACA0012- $\alpha$ and NACA0012- $\beta$ blade profiles

\subsection{Numerical Optimization}

The profile geometry obtained as a result of parametric studies continued to be improved with the Adjoint Solver module in Ansys/Fluent software at a fixed Reynolds number in 16000-32000 range and turbulent intensity in $4.4-4.8 \%$ range. Operating the design parameters independently, the adjoint approach is an optimization method based on the optimal calculation of gradients remaining within a specifically defined calculation region. Gradients which were mesh nodes on the calculation area are calculated in the normal direction according to point motion [21]. Adjoint solver module is an optimization method which allows the deformation of the mesh within a specified calculation area in order to maximize or minimize the defined parameters. To that end, it was aimed to maximize the lift-to-drag ratio within the calculation area containing blade profile geometry by maximizing lift coefficient and minimizing drag coefficient. As shown in Fig. 4, a region where the change of profile mean line and thickness would remain $\pm 40 \%$ was defined within the computational area. This identified region was deformed to maximize the lift-to-drag ratio during CFD analyses. The 
advantage of the method is that it is able to optimize the profile by solving equations within the defined area without having to resolve the entire calculation area in the CFD analysis as in the parametric study.

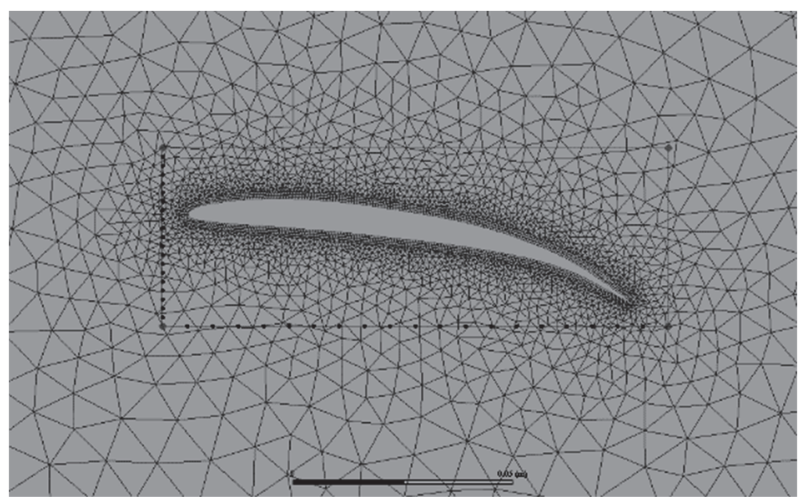

Figure 4 Calculation area that can be deformed in the adjoint solver method

The formula in Eq. (8) describes the change in the liftto-drag ratio from node displacements and shape sensitivity coefficients. Solver has ability to estimate the change in lift-to-drag ratio produced by the airfoil owing to the geometric change made by the solver. This is done by summing up the sensitivities at each node multiplied by the displacement at each node as per the Eq. (8). Thus, it is possible to find out how much deformation is required to obtain the desired lift-to-drag rate.

$\delta\left(C_{\mathrm{L}} / C_{\mathrm{D}}\right)=\sum_{\mathrm{mesh}} w^{n} \cdot \delta x^{n}$

Lift and drag coefficients can be expressed as in Eq. (9) and (10).

$$
\begin{gathered}
C_{\mathrm{L}}=\frac{F_{\mathrm{L}}}{\frac{1}{2} \rho A v_{\infty}^{2}} \\
C_{\mathrm{D}}=\frac{F_{\mathrm{D}}}{\frac{1}{2} \rho A v_{\infty}^{2}}
\end{gathered}
$$

where $A$ is the frontal area of the VAWT, $\rho$ is the density of the air, $v_{\infty}$ is the wind velocity, $F_{\mathrm{L}}$ and $F_{\mathrm{D}}$ are the lift and drag force, respectively.

As a result of parametric studies on the NACA0012 blade profile, which was initially referenced, the optimized profile obtained was named NACA0012- $\alpha$ and the new profile geometry developed by the numerical method using this profile was called NACA0012- $\beta$. The profile geometries are shown in Fig. 5. The maximum lift-to-drag ratio value obtained by parametric and numerical optimization is 6.24 and 6.43 , respectively. In both NACA0012- $\beta$ and NACA0012- $\alpha$ profiles increase in liftto-drag ratio was approximately equal. The increment in lift-to-drag ratio was achieved mainly by decreasing the drag coefficient for the NACA0012- $\beta$ profile, while the increase in the lift coefficient for the NACA0012- $\alpha$ profile was dominant.

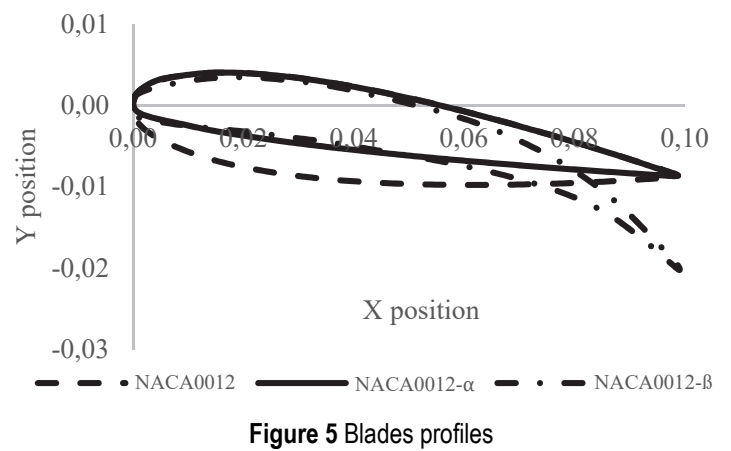

\section{EXPERIMENTAL STUDY}

The performance of the VAWT with blade profiles obtained from the optimization studies was experimentally analyzed. For this purpose, the entire plastic part of the VAWT (Polymer acid, PLA) was produced by using a 3D printer (Zaxe X1) by joint production method. In order to perform experimental studies Reynolds number in the range 16000-32000, a vertical axis H-type wind turbine with a blade length of $0.56 \mathrm{~m}$ attack angle of $5^{\circ}$ chord length of $0.08 \mathrm{~m}$ and a rotor diameter of $0.42 \mathrm{~m}$ was designed modularly.

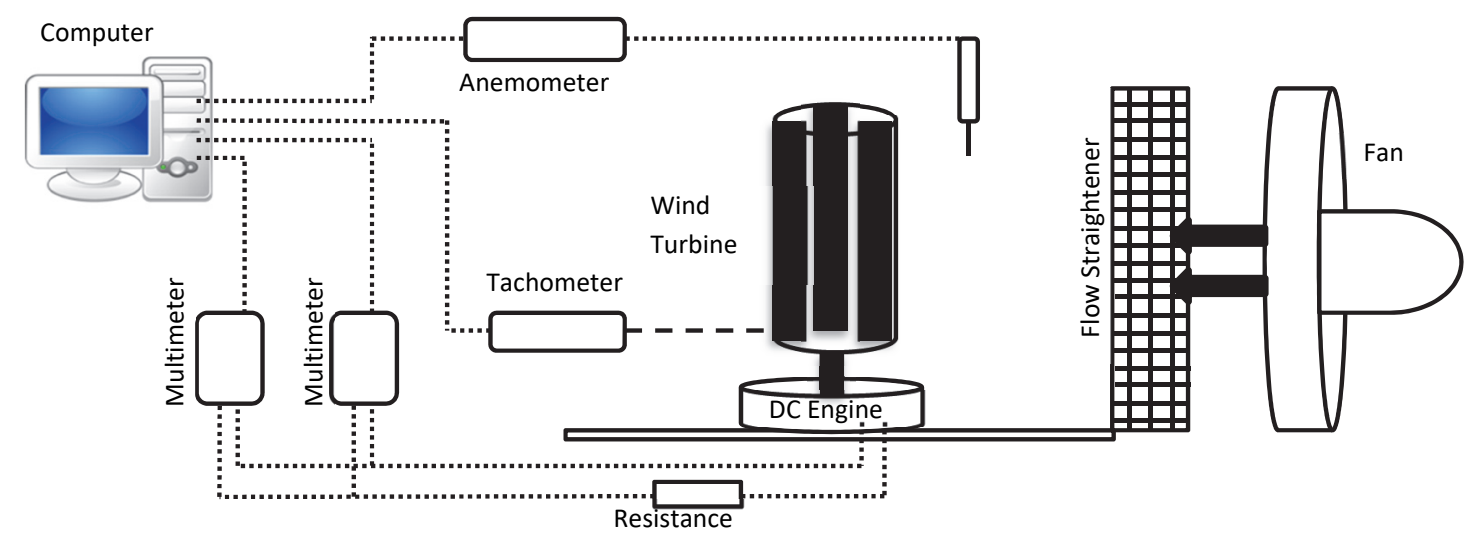

Figure 6 The experimental test setup scheme

The experimental setup is shown in Fig. 6. When turbine dimensions were taken into consideration, two fans with a flow rate of $17400 \mathrm{~m}^{3} / \mathrm{h}$ (Bahcivan, BVN-BSV-750) were used side by side to generate the air flow to the turbine. The data of the air flow generated in the experimental setup was obtained with a handheld digital 
anemometer (Lutron AM-4206). An optical non-contact tachometer (Uni-T UT372) was used to measure the turbine speed. Current $(I)$ and voltage $(V)$ produced by the turbine were measured by two separate Digital Multimeters (Brymen BM525s). During the experiment, instantly measured data were transferred to the computer. $24 \mathrm{~V} 50$ W DC motor ( $2900 \mathrm{~d} / \mathrm{min}$, Kormas) connected to the wind turbine as a generator to produce electrical energyThe position where the anemometer probe is located is extremely important. The anemometer probe can be located at a distance from the wind turbine of between 2 and 4 times the specific length $(L)$. In the case of VAWT, this specific length is defined as equal to $2 A / \pi$. In the experimental study, this distance was taken as $2.5 \mathrm{~L}$ [22].

In the experimental setup, separate experiments were conducted for 3, 4 and 5 blades with NACA0012, NACA0012- $\alpha$, and NACA0012- $\beta$ profiles. Experiments were repeated 8 times for each set. The power coefficient $\left(C_{\mathrm{p}}\right)$ of the VAWT depends on the electrical and wind power and can be defined as [22];

$$
C_{\mathrm{p}}=\frac{P_{\mathrm{e}}}{\eta_{\mathrm{g}} \cdot P_{\infty}}
$$

In the equation $\left(\eta_{\mathrm{g}}\right)$ is the generator efficiency, $\left(P_{\mathrm{e}}\right)$ and $\left(P_{\infty}\right)$ are the electrical and wind power, respectively. Mechanical losses are neglected since torque is transferred directly to the generator via a short shaft without any coupling, clutch or gear system. Therefore, in equation 12 only the generator efficiency is used. Since direct current (DC) engine was used, electrical power $\left(P_{\mathrm{e}}\right)$ as a function of current and voltage was calculated by using Eq. (12). Wind power was obtained by Eq. (13)

$P_{\mathrm{e}}=I \cdot V$

$P_{\infty}=\frac{1}{2} \rho A v_{\infty}^{3}$

In the study, the average power outputs from the VAWT have been shown in dimensionless form as follows:

$$
C_{\mathrm{p}, \text { avg. }}=\frac{\int_{0}^{2 \pi} \frac{P_{\mathrm{e}, \theta}}{\frac{1}{2} \rho A v_{\infty}^{3} \eta_{\mathrm{g}}} d \theta}{n}
$$

where $\theta$ is the angular position of the VAWT, $P_{\mathrm{e}, \theta}$ is the kind of power depending on the angular position and $n$ is the number of time steps when it is rotated to complete one revolution.

\subsection{Uncertainty Analysis}

Deviation of the measuring instruments used in experimental studies is $\pm(2 \%+0.2 \mathrm{~m} / \mathrm{s})$ for anemometer (Lutron AM-4206), $\pm(0.04 \%+2)$ for tachometer (UNI-T UT 372) and $(V ; 0.08 \%+2 d, I ; 0.2 \%+4 d)$ for Multimeter (Brymen BM525s). The error rate for the power coefficient $\left(W_{C \mathrm{p}}\right)$ was obtained using Eq. (15) depending on the current, voltage and wind speed, and the error rate for the
TSR $\left(W_{\lambda}\right)$ was obtained using Eq. (16) based on wind speed and angular speed. The error rates for the power coefficient and TSR were calculated as $\pm 3.8 \%$ and $\pm 6.9 \%$, respectively

$$
\begin{aligned}
& W_{C_{\mathrm{p}}}=\left(\left(\frac{\partial P}{\partial I} W_{I}\right)^{2}+\left(\frac{\partial P}{\partial V} W_{V}\right)^{2}+\left(\frac{\partial P}{\partial u} W_{u}\right)^{2}\right)^{0.5} \\
& W_{\lambda}=\left(\left(\frac{\partial \lambda}{\partial \omega} W_{\omega}\right)^{2}+\left(\frac{\partial \lambda}{\partial u} W_{u}\right)^{2}\right)^{0.5}
\end{aligned}
$$

\section{RESULTS}

New profiles have been developed by parametric (NACA0012- $\alpha$ ) and numerical (NACA0012- $\beta$ ) optimization methods from the reference (NACA0012) profile and tested under 3, 4 and 5 bladed conditions in the VAWT. Power values were measured from VAWT with NACA0012, NACA0012- $\alpha$ and NACA0012- $\beta$ profiles, depending on the TSR.

The power data measured for the NACA0012 profile by taking the number of the blades as a parameter is shown in Fig. 7. The maximum power coefficient for 3-bladed turbine was obtained at $2.12 \mathrm{TSR}$, while the maximum power coefficient for 4 and 5-bladed turbines was obtained at 1.94 and 1.09 TSR values, respectively. The highest power coefficient values were measured from 4 bladed turbines. It has been obtained that the maximum power coefficient value is 0.19 for 4-bladed turbine, while those for 3 and 5-bladed turbines were observed as 0.16 and 0.17 , respectively. Compatible with the literature, the maximum power coefficient decreased as the number of blades increased after a critical solidity value. Additionally, the maximum power coefficient is obtained at lower TSR values, as the number of blades increases [23].

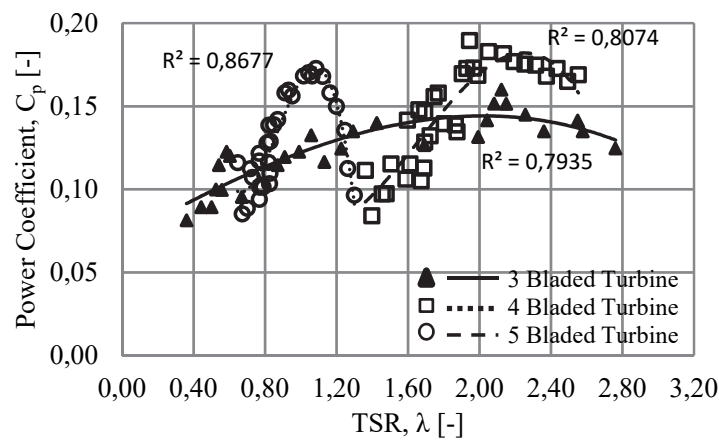

Figure 7 Variation of power coefficient obtained from a NACA0012 profile according to blade TSR

Power values obtained from turbines with NACA0012- $\alpha$ profile are shown in Fig. 8. The turbine using the NACA0012- $\alpha$ profile has reached a maximum power value at a relatively low TSR compared to those using the NACA0012 profile. The highest power coefficient for the 3-bladed turbine was obtained at 1.33 TSR value, while it was obtained at 1.52 TSR for the 5bladed turbine. The highest power coefficient of 0.24 was obtained at 1.65 TSR for 4-bladed turbine. 


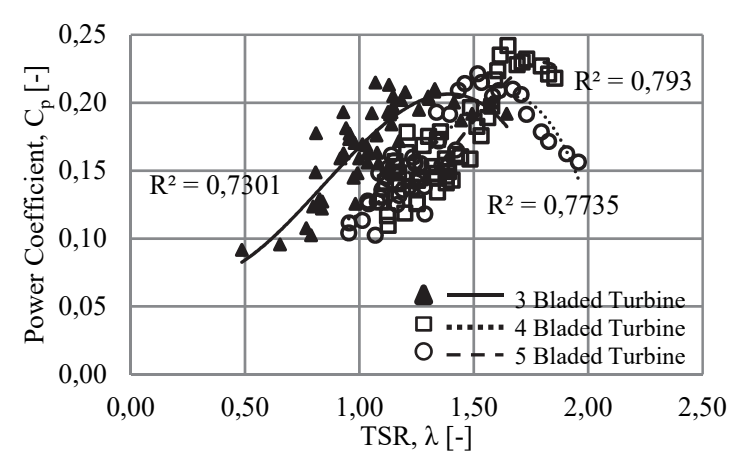

Figure 8 Variation of power coefficient obtained from a NACA0012- $\alpha$ profile according to blade TSR

The power coefficient values of the NACA0012- $\beta$ profile are given in Fig. 9. In the experimental study performed by taking the number of the blades as a parameter, the maximum power coefficient was determined as 0.22 at 1.64 TSR for 3-bladed turbine. The highest power coefficient for the 4 and 5-bladed turbines was 0.30 at 1.79 TSR and 0.24 at 1.50 TSR, respectively. Similar to the other profiles, the highest power coefficient was obtained from 4-bladed turbines for numerically optimized profile. TSR at which maximum power coefficient was obtained, and the number of the blades were found to be inversely proportional till the critical solidity value, i.e. 0.76 for NACA0012- $\beta$. After a solidity value of 0.76 , increase in solidity leads to a decrease in the power coefficient obtained from the VAWT.

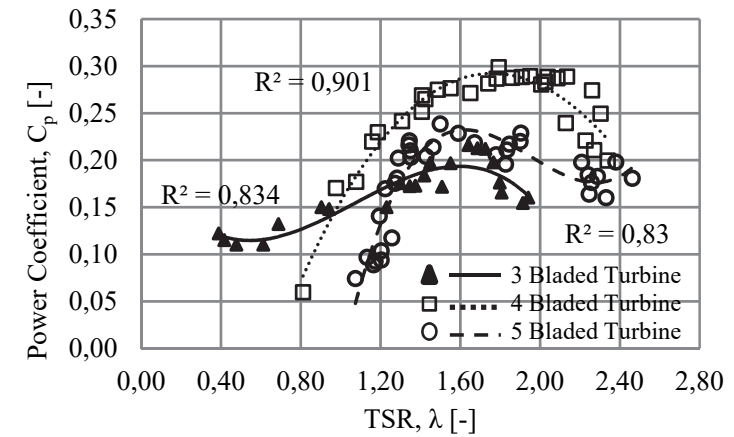

Figure 9 Variation of power coefficient obtained from a NACA0012- $\beta$ profile according to TSR

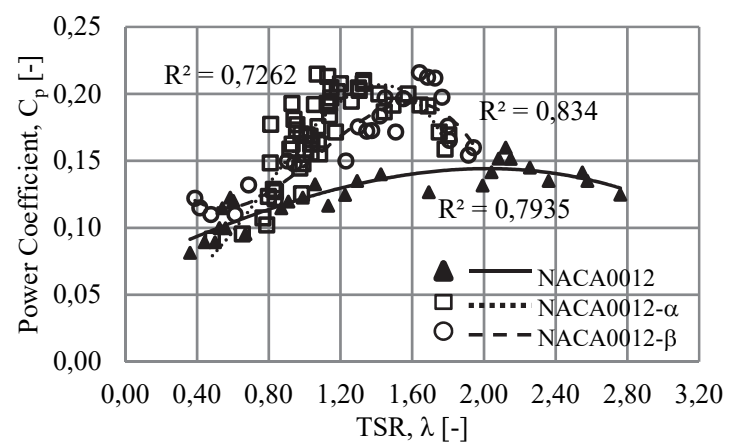

Figure 10 Variation of power coefficient in 3-bladed turbine depending on the TSR

The variation of the power coefficient values versus the TSR for all profiles is shown in Figs. 10 to 12. In 4bladed turbine, the highest power coefficient was obtained from all profiles. Owing to optimization, higher power coefficient values were obtained at lower TSR. The power coefficients obtained from NACA0012- $\alpha$ and NACA0012- $\beta$ are 0.24 and 0.30 , respectively, under conditions where a power coefficient of 0.19 is obtained from the reference profile. A remarkable performance increase is achieved in turbines using the profile derived from numerical optimization.

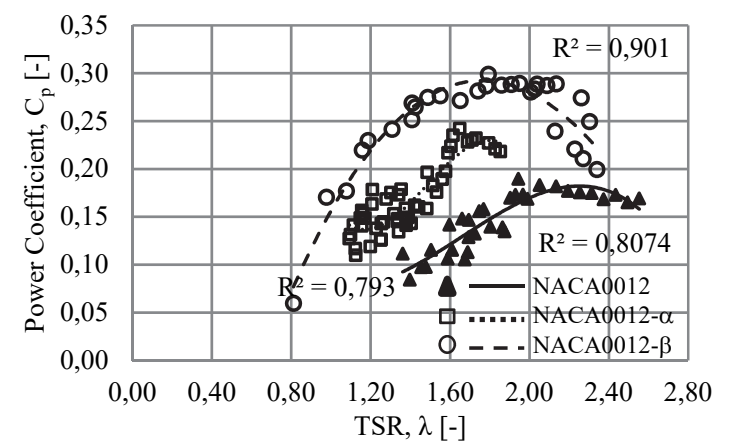

Figure 11 Variation of power coefficient depending on TSR in 4-bladed turbine

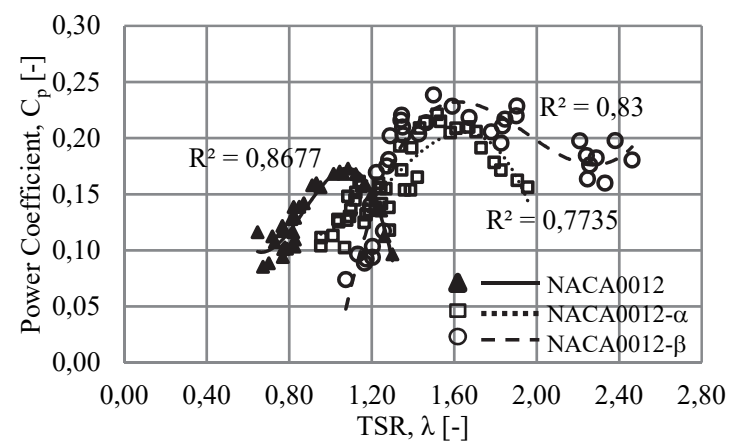

Figure 12 Variation of the power factor in a five-bladed turbine depending on the TSR

\section{CONCLUSIONS}

In this study, parametric and numerical optimization of the reference profile (NACA 0012) was performed by using CFD analysis. New profiles were derived by using lift coefficient, drag coefficient, and lift-to-drag ratio as the parameters. Experimental studies were carried out for 3, 4, and 5 blade situations in the $H$ type Darrieus wind turbine, and the performance of the turbine was tested. This study can be concluded as follows:

When the solidity value increased, the maximum power coefficient values were reached at lower TSR. But, once the solidity value exceeds 0.76 which is the critical value for current study, the increase in the solidity reduces the power coefficient.

The lift-to-drag ratio of the reference profile was increased from 3.92 to 6.24 by parametric optimization (NACA0012- $\alpha$ ) and to 6.43 by numerical optimization (NACA0012- $\beta$ ). Although the lift-to-drag ratio was close to each other in both profiles, the blade profile (NACA $0012-\beta$ ) derived by numerical optimization reached a $26 \%$ higher power coefficient than the blade profile (NACA $0012-\alpha$ ) derived by parametric optimization. This can be explained by considering the lift and drag coefficient, which are the components of the lift-to-drag ratio, separately. In the NACA $0012-\beta$ profile, the lift-to-drag ratio has been increased with an increase in the lift coefficient, due to the tail taking the shape of a flap. On the other hand, because of the decrease in profile thickness in the NACA 0012- $\alpha$ profile, the lift-to-drag ratio has been 
increased with a decrease in the drag coefficient. Therefore, it can be concluded that the lift coefficient is more effective on the power coefficient than the drag coefficient

In the optimization process, the lift-to-drag ratio of the reference profile has been significantly increased for both the NACA $0012-\alpha$ and NACA0012- $\beta$ profiles. However, this increase in the lift-to-drag ratio was only reflected in the increase in power coefficient value of the wind turbine as 0.08 and 0.14 points for NACA $0012-\alpha$ and NACA0012$\beta$ profiles, respectively. This can be explained by the difference between the conditions of the optimization process and the performance tests. In the CFD analysis of the optimization study in which the profiles are derived, the lift-to-drag ratio is obtained from the two-dimensional static conditions. In other words, the maximum lift-to-drag ratio is obtained over the static blade. But, power performance characteristics of the optimized profile used in the VAWT were obtained under dynamic conditions. In these conditions, the attack angle of the blade changes for each position of the turbine rotor, due to the angular movement of the turbine about its axis. Therefore; the liftto-drag ratio for a cycle of the blade in a VAWT does not always have the same effect on the obtained power value. It is generally preferred practice to perform this process under static conditions in order to avoid the difficulties of performing optimization under dynamic conditions. However, this study shows that an optimization study carried out under static conditions cannot be fully met under dynamic conditions. Therefore, it can be suggested for future studies to keep in mind that developing a correlation between the lift-to-drag ratio and the power coefficient of the VAWT is important.

\section{Acknowledgements}

This study was supported by Sakarya University Scientific Research Projects Coordinatorship as a Master's Thesis Project (Project Number: 2017-50-01-055).

\section{Nomenclature}

A Frontal area of turbine $/ \mathrm{m}^{2}$

$C_{\mathrm{L}}, C_{\mathrm{D}}$ Lift and drag coefficients / -

$C_{\mathrm{P}} \quad$ Power coefficient / -

CFD Computational fluid dynamics

DC Direct current

$F_{\mathrm{L}}, F_{\mathrm{D}} \quad$ Lift and drag forces $/ \mathrm{N}$

$I \quad$ Current / A

$k \quad$ Turbulent kinetic energy $/ \mathrm{m}^{2} \mathrm{~s}^{-2}$

NACA National advisory committee for aeronautics

$P_{\mathrm{e}} \quad$ Power of the system $/ \mathrm{Nms}^{-1}$

$P_{\infty} \quad$ Power of the wind $/ \mathrm{Nms}^{-1}$

$R \quad$ Radius of the rotor $/ \mathrm{m}$

RSO Respond surface optimization

$u, v \quad$ Components of the displacement in the $x$ and $y$ directions $/ \mathrm{ms}^{-1}$

$v_{\infty} \quad$ Velocity of the wind $/ \mathrm{ms}^{-1}$

V Voltage / V

VAWT Vertical axis wind turbine

$\omega \quad$ Angular velocity $/ \mathrm{rad} \cdot \mathrm{s}^{-1}$

$W \quad$ Error rate / -

$\varepsilon \quad$ Turbulent dissipation rate $/ \mathrm{m}^{2} \mathrm{~s}^{-3}$ $\eta_{\mathrm{m}, \mathrm{e}} \quad$ Turbine system efficiency / -

$\lambda \quad$ Tip-speed ratio (TSR) / -

$\mu \quad$ Dynamic viscosity of air / Pa $\cdot \mathrm{s}$

$\mu_{\mathrm{t}} \quad$ Turbulent viscosity $/ \mathrm{m}^{2} \mathrm{~s}^{-1}$

$\rho \quad$ Density of the air $/ \mathrm{kgm}^{-3}$

$\sigma_{k}, \sigma_{\varepsilon} \quad$ Turbulent Prandtl number for $k$ and $\varepsilon /$ -

\section{REFERENCES}

[1] Fatehi, M., Nili-Ahmadabadi, M., Nematollahi, O., Minaiean, A., \& Kim, K. C. (2019). Aerodynamic performance improvement of wind turbine blade by cavity shape optimization. Renewable Energy, 132, 773-785. https://doi.org/10.1016/j.renene.2018.08.047

[2] Chan, C. M., Bai, H. L., \& He, D. Q. (2018). Blade shape optimization of the savonius wind turbine using a genetic algorithm. Applied Energy, 213, 148-157. https://doi.org/10.1016/i.apenergy.2018.01.029

[3] Ramadan, A., Yousef, K., Said, M., \& Mohamed, M. H. (2018). Shape optimization and experimental validation of a drag vertical axis wind turbine. Energy, 151, 839-853. https://doi.org/10.1016/j.energy.2018.03.117

[4] Marinic-Kragic, I., Vucina, D., \& Milas, Z. (2018). Numerical workflow for 3D shape optimization and synthesis of vertical-axis wind turbines for specified operating regimes. Renewable Energy, 115, 113-127. https://doi.org/10.1016/j.renene.2017.08.030

[5] Erisen, A. \& Bakirci, M. (2014). Modifications of NACA0012, NACA4412airfoils and analysis them by CFD. Journal of Engineering and Technological Sciences, 2(1), 50-82.

[6] Li, C., Xiao, Y., Xu, Y., Peng, Y., Hu, G., \& Zhu, S. (2018). Optimization of blade pitch in H-rotor vertical axis wind turbines through computational fluid dynamics simulations. Applied Energy, 212, 1107-1125. https://doi.org/10.1016/j.apenergy.2017.12.035

[7] Karimian, S. M. H. \& Abdolahifar, A. (2020). Performance investigation of a new Darrieus type vertical axis wind turbine. Energy, 191, 1-18. https://doi.org/10.1016/j.energy.2019.116551

[8] Zhang, T., Wang, Z., Huang, W., Ingham, D., Ma, L., \& Pourkashanian, M. (2020). A numerical study on choosing the best configuration of the blade for vertical axis wind turbines. Journal of Wind Engineering \& Industrial Aerodynamics, 201, 1-12. https://doi.org/10.1016/j.jweia.2020.104162

[9] Masdari, M., Tahani, M., Naderi, M. H., \& Babayan, N. (2019). Optimization of airfoil based savonius wind turbine using coupled discrete vortex method and salp swarm algorithm. Journal of Cleaner Production, 222, 47-56. https://doi.org/10.1016/j.jclepro.2019.02.237

[10] Jafaryar, M., Kamrani, R., Gorji-Bandpy, M., Hatami, M., \& Ganji, D. D. (2016). Numerical optimization of the asymmetric blades mounted on a vertical axis cross-flow wind turbine. International Communications in Heat and Mass Transfer, 70, 93-104. https://doi.org/10.1016/j.icheatmasstransfer.2015.12.003

[11] Gomec, F. S. (2014). Performance prediction of darrieus type vertical axis wind turbines using numerical simulations. Ankara, Turkey: Master's thesis, Middle East Technical University.

[12] Castelli, M. R., Betta, S. D., \& Benini, E. (2012). Effect of blade number on a straight blade vertical axis darrieus wind turbine. World academy of science, engineering and technology. International Journal of Mechanical, Aerospace, Industrial, Mechanical and Manufacturing Engineering, 6(1), 68-74. 
[13] Lee, Y. T. \& Lim, H. C. (2016). Power performance improvement of $500 \mathrm{~W}$ vertical axis wind turbine with salient design parameters, World Academy of Science, Engineering Technology. International Journal of Mechanical and Mechatronics Engineering, 10(1), 84-88. https://doi.org/10.5281/zenodo.1338648

[14] Bekka, N., Bessaih, R., Sellam, M., \& Chpoun, A. (2010). Numerical study of heat transfer around the small-scale airfoilusing various turbulence models. Heat Transfer, Part A: Applications, 56(12), 946-969. https://doi.org/10.1080/10407780903508005

[15] Sabaeifard, P., Razzaghi, H., \& Forouzandeh, A. (2012). Determination of vertical axis wind turbines optimal configuration. International Conference on Future Environment and Energy IPCBEE, 28, 109-113.

[16] Yilmaz, I., Cam, O., Tastan, M., \& Karci, A. (2016). Experimental investigation of aerodynamic performance of different wind turbines airfoils. Journal of Polytechnic, 19(4), 577-584.

[17] Yao, J., Yuan, W., Wang, J. Xie, J., Zhou, H., Peng, M., \& Sun, Y. (2012). Numerical simulation of aerodynamic performance for two-dimensional wind turbine airfoils.Procedia Engineering, 31, 80-86. https://doi.org/10.1016/j.proeng.2012.01.994

[18] Sahin, I. \& Acir, A. (2015). Numerical and experimental investigations of lift and drag performances of naca 0015 wind turbine airfoil. International Journal of Materials, Mechanics and Manufacturing, 3(1), 22-25. https://doi.org/10.7763/IJMMM.2015.V3.159

[19] ANSYS Inc. (2013). Ansys Fluent Theory Guide: Release 15.0. Canonsburg, PA: Ansys Inc.

[20] Cengel, Y. A. \& Cimbala, J. M. (2013). Fluid Mechanics: Fundemantal and Applications. New York, NY: McGrawHill Companies.

[21] Schramm, M., Stoevesandt, B., \& Peinke, J. (2018). Optimization of airfoils using the adjoint approach and the influence of adjoint turbulent viscosity. Computation, 6(5). https://doi.org/10.3390/computation6010005

[22] International Std. IEC61400-12-1 (2.0b) (2017). Wind Turbines-Power performance measurements of electricity producing wind turbine: Second Edition. International Electrotechnical Commission IEC.

[23] Saryazdi, S. M. E. \& Boroushaki, M. (2018). 2D numerical simulation and sensitive analysis of h-darrieus wind turbine. International Journal of Renewable Energy Development (IJRED), 7(1), 23-34.

\section{Contact information:}

Cemil YIĞIT, Asst. Professor

(Corresponding author)

Sakarya University, Faculty of Engineering,

Department of Mechanical Engineering,

54187, Sakarya, Turkey

E-mail: cyigit@sakarya.edu.tr

Erdem AKMAN, MSc. Eng.

Sakarya University, Institute of Natural Science,

Program of Mechanical Engineering,

54187, Sakarya, Turkey

E-mail: erdemakman1@gmail.com 